\title{
Editorial
}

\section{Editorial: Computational Thinking in Education}

\author{
Betül C. Czerkawski \\ Editor, ITET
}

\author{
Eugene W. Lyman \\ Managing Editor, ITET
}

\begin{abstract}
Effort is still needed to make computational thinking (CT) a 21st century skill taught widely across multiple subjects. Since using or solving problems with computers is not specific to any single discipline, we can expect that in the near future, there will be further interdisciplinary research to understand the impact of computation across a range of academic fields. Our hope is that as more Special Issues like ours, or books and articles are published, the field will mature and provide datadriven support to curriculum design and assessment efforts.
\end{abstract}

Keywords: computational thinking; curriculum; K-12 education; research

In our editorial last fall, we discussed the current status of educational computing; we argued that effort is still needed to make computational thinking (CT) a 21st century skill taught widely across multiple subjects. We also announced our first Special Issue on computational thinking, because we believe that in order to realize the promise of CT, disciplines outside of computer science must also adopt it. Today, we are pleased that scholars from various disciplines are approaching this new area of study with enthusiasm and are conducting cross-disciplinary research to better understand its potential.

The core mental skill used in computational thinking is abstraction. Abstraction is creating algorithms or sequenced steps to produce desired outcomes (Wing, 2008). For many years, educators and researchers thought mathematicians, computer scientists or other physical scientists needed abstract and algorithmic thinking skills. Not all students needed to learn these high level skills to succeed in their fields. In our increasingly digitalized and technology-oriented world, however, we talk about computational biology (or bioinformatics), computational statistics (e.g. machine learning), computational microeconomics, and digital humanities. All of these intersect with the idea of computational thinking, which requires students to learn the main principles of "solving problems with...computers." Since using or solving problems with computers is not specific to any single discipline, we can expect that in the near future, there will be further interdisciplinary research to understand the impact of computation across 
a range of academic fields. The question, however, is how these efforts will transform the current educational landscape, since the increased need for computational thinking presents a new challenge for $\mathrm{K}-12$ schools and universities.

Education, as a system, has been slow to adapt to social change. This time the challenge is immediate and urgent: societies need digitally savvy citizens who can interpret massive flows of new information; businesses require skilled workers who can keep up with current technological advances in the marketplace. Non-profit organizations such as Google.org, the Mozilla Foundation and Code.org, as well as professional organizations such as ISTE (International Society for Technology in Education) or CSTA (Computer Science Teachers Association) are leading the way, so that CT can become an accessible skill for everybody. Community-based events such as Hackathons and Hour of Code events are also becoming more widespread and are increasing students' exposure to programming. Educators are also catching up with these recent developments, though curricular integration is still not part of many teacher education programs (Czerkawski, 2016). A recent report published by Google (2015) noted that almost half of the country's $\mathrm{K}-12$ schools do not offer computer science courses. Where computer science courses are offered, nearly half do not offer programming content.

Our hope is that as more Special Issues like ours, or books and articles are published, the field will mature and provide data-driven support to curriculum design and assessment efforts. As the editors of ITET we invite all scholars from various fields to use our journal as a platform to share and distribute their research on computational thinking.

\section{References}

Czerkawski, B. (2016). Computational thinking and teacher education: Are we there yet?. In Proceedings of Society for Information Technology \& Teacher Education International Conference 2016 (pp. 75-78). Chesapeake, VA: Association for the Advancement of Computing in Education (AACE).

Google (2015). Searching for computer science: Access and barriers in U.S. K-12 education. Available at: https://services.google.com/fh/files/misc/searching-forcomputer-science_report.pdf.

Wing, J. M. (2008). Computational thinking and thinking about computation. Philosophical Transactions of the Royal Society. 366. 3717-3725. Available at http://www. cs.cmu.edu/ wing/publications/Wing08a.pdf. 